\title{
TURBULENCE STRUCTURE AND EXCHANGE PROCESSES IN AN ALPINE VALLEY The Riviera Project
}

\author{
by Mathias W. Rotach, * Pierluigl Calanca, Giovanni Graziani, Joachim Gurtz, D. G. Steyn, \\ Roland Vogt, Marco Andretta, Andreas Christen, Stanislaw Cieslik, Richard Connolly, \\ Stephan F. J. De Wekker, ${ }^{+}$Stefano Galmarini, Evgeny N. Kadygrov, Vladislav Kadygrov, \\ Evgeny Miller, Bruno Neininger, Magdalena Rucker, Eva Van Gorsel, \\ Heidi Weber, AleXandra Weiss, and Massimiliano Zappa
}

The new detailed data set resulting from this field campaign, set in highly complex terrain, is helping improve turbulence schemes in meteorological and hydrological numerical models.

$\mathrm{L}$ ocal circulation systems and average temperature and stratification conditions in valleys have been investigated in some detail in the past, and are fairly well understood at present (e.g., Whiteman 1990, 2000). In contrast, little has been done with respect to the associated turbulence structure and turbulent exchange processes in mountainous terrain (Rotach et al. 2000). Even from relatively recent large field programs, such as the Atmospheric Studies over
Complex Terrain (ASCOT) program (Clements et al. 1989), only a few "representative" turbulence observations are available.

Often, the emphasis of atmospheric studies in mountainous terrain is focused on pollutant transport [e.g., Anfossi et al. (1998) for the Trans-Alpine Atmospheric Transport experiment (TRANSALP); Cionco et al. (1999) for the Meteorology and Diffusion over Non-Uniform Areas (MADONA) study] or
AfFiliations: Rotach, Calanca, Gurtz, Andretta, Weber, WEISS, AND ZAPPA-Institute for Atmospheric and Climate Science, Swiss Federal Institute of Technology, Zurich, Switzerland; VoGT, ChrISTEN, AND VAN GoRSEL-MCR Laboratory, University of Basel, Basel, Switzerland; STEYN, DE WEKKER, AND RUCKER-Atmospheric Science Program, The University of British Columbia, Vancouver, British Columbia, Canada; Graziani, Cieslik, Connolly, And GALMARINI-Joint Research Center, Ispra, Italy; E. N. KADYGROV, V. KADYGROV, AND MILleR-Central Aerological Observatory, Moscow, Russia; NeININGer-MetAir, Illnau, Switzerland

*Current affiliation: Swiss Federal Office for Meteorology and
Climatology, MeteoSwiss, Zurich, Switzerland

+Current affiliation: Pacific Northwest National Laboratory, Richland, Washington

\#Present affiliation: MPI, Hamburg, Germany

CORRESPONDING AUTHOR: Mathias W. Rotach, Swiss Federal Office for Meteorology and Climatology, MeteoSwiss, Kraebuehlstr. 44, P.O. Box 5I4, CH-8044 Zurich

E-mail: mathias.rotach@meteoswiss.ch

DOI:10.1 I75/BAMS-85-9-1367

In final form 12 January 2004

(2004 American Meteorological Society 
atmospheric chemistry. For example, in the Vertical Ozone Transport in the Alps (VOTALP) campaign surface turbulence information was available at only two selected sites within the Mesolcina valley (Furger et al. 2000). Because pollutant distribution over any type of terrain is largely determined by turbulent exchange processes and their interaction with the mean flow, it is clear that there is a need to understand turbulence in complex terrain. What we do know, concerning turbulence structure in an alpine valley, is that commonly used approaches in boundary layer meteorology (such as the validity of scaling regimes; Holtslag and Nieuwstadt 1986) cannot be expected to hold, due to the violation of many underlying assumptions. For flows over gentle hills linearized models and scaling considerations based thereupon are available, which identify different scaling regimes (e.g., Jackson and Hunt 1975; Belcher and Hunt 1998), but these cannot be expected to apply over steep mountains. Most theoretical work concerning valleys is devoted to the thermodynamics of local circulation due to differential heating (e.g., Vergeiner 1987). In these studies the contribution of turbulent exchange is usually treated in a very simplistic manner.

Numerical models of all scales-numerical weather prediction, climate, mesoscale, and large eddy simulation models-use parameterizations, which are based on scaling approaches for flat and horizontally homogeneous terrain in their surface exchange and boundary layer schemes (Randall 2001; Beljaars and Viterbo 1998; Emeis and Rotach 1997). Large-scale models having a horizontal resolution of $100 \mathrm{~km}$ or more will not resolve many of the orographic features of complex topography. In their highly smoothed topography the first model level at typically $30 \mathrm{~m}$ above "ground" would need a parameterization to account for bulk turbulent exchange from a series of valleys and ridges. Rather, they have at present a surface layer description based on the Monin-Obukhov similarity theory (e.g., Louis 1979). This leads to sometimes unrealistically high values of the effective roughness length (e.g., Georgelin et al. 1994). Similarly, nonhydrostatic models with high horizontal resolution use the same surface exchange schemes over the valley slope, valley floor, and nearby ridges irrespective of their having been developed for flat, horizontally homogeneous terrain.

Hydrological models for the prediction of runoff in entire catchments typically use even more simplified surface layer schemes to obtain surface fluxes of sensible and latent heat from energy balance considerations (e.g., Gurtz et al. 1999). For such simulations, where mountainous terrain is not the exception but the rule, it is clear that these approaches may sometimes be problematic (e.g., Plüss and Mazzoni 1994), but, little data are presently available to improve these schemes.

The use of these surface exchange and boundary layer schemes in numerical models can easily be criticized based on first principles, but they are employed only due to the lack of better knowledge (Rotach 1995). As a step toward filling this gap, the Riviera project was planned and executed in conjunction with the Mesoscale Alpine Programme (MAP), an international research effort to improve our knowledge of meteorological and hydrological processes over the Alps (Binder and Schär 1996; Bougeault et al. 2001). It was decided to investigate one valley in detail, rather than a number of topographical features with different sizes, orientation, and other characteristics (Emeis and Rotach 1997). Therefore, a wide range of instrumentation was deployed in a single valley in the southern Alps.

SITE SELECTION. To link this research with hydrological components of the project, a test valley was sought in the Lago Maggiore target area of MAP (Bougeault et al. 2001). The following valley selection criteria were applied:

a) valley structure: as unobstructed, straight, and symmetric as possible with equal height and slopes on both sides, and few side valleys;

b) valley size: a small valley, with respect to optimal spatial resolution, given the limited instrumentation available [However, it was felt that a valley with a width comparable to the resolution of modern operational models (e.g., the highest resolution Swiss operational model: $7 \mathrm{~km}$ ) was preferable]; and

c) infrastructure: availability of suitable, easily accessible experimental sites on the slope(s).

Based on these criteria the Riviera valley in southern Switzerland was chosen. It constitutes a part of the Ticino valley (Fig. 1) between Bellinzona and Biasca that discharges from the Saint Gotthard massif in the central Alps to Lago Maggiore. It is approximately straight and U-shaped, with a floor ranging from about $250 \mathrm{~m}$ above sea level (ASL) to ridge tops at about $2500 \mathrm{~m}$ ASL on both sides. The valley floor is $1.5 \mathrm{~km}$ wide, and the slopes are roughly $30^{\circ}$ and $35^{\circ}$ on the eastern and western sides, respectively. The Riviera valley contains some minor tributary valleys on both sides.

The valley floor consists of agricultural land and a number of villages and isolated farmhouses. A high- 
way, a railroad, and the Ticino River run along the valley axis. The slopes are mainly forest covered. Above roughly $1200 \mathrm{~m} \mathrm{ASL}$, meadows are interspersed with rocky rubble. One special feature of the Riviera valley is the fact that its outflow leads to another valley rather than the "classical" plain. This clearly influences the flow (Weigel and Rotach 2003) and will have to be analyzed in detail in the future.

OBSERVATIONAL STRATEGY. Some of the "continuous observations," as described in the following similarly titled section, started as early as 10 July 1999 and were operating until 13 October 1999. The majority of instrumentation at the continuous sites was active from the beginning of August to the beginning of October 1999. Due to power outages at some of the remote sites, not all instruments were continuously recording in this period. Two intensive observation periods (IOPs) were scheduled to coincide with the availability of the research aircraft (Research flights section). These periods lasted from 15 to 31 August and from 20 September to 8 October 1999 and are referred to as R-IOP1 and R-IOP2, respectively. A total of 14 flights of 2-4 h duration each were performed on eight flight days, with all of the "additional instrumentation" (Table 2, see sections on Scintillometry through Sodar for details) then being available. Figure 2 depicts the topography of the Riviera valley and indicates the main cross section of observations near Claro (close to sites A1 and A2), a small village at the foot of the eastern slope. Shown are the continuous sites and the distribution of additional instrumentation during the IOPs. Full detail concerning the observations (instrument levels, sampling frequencies, instrument types, and calibrations, etc.) can be found on the project's homepage (online at www.iac.ethz.ch/ en/research/map_riviera/index.html), under "metadata report."

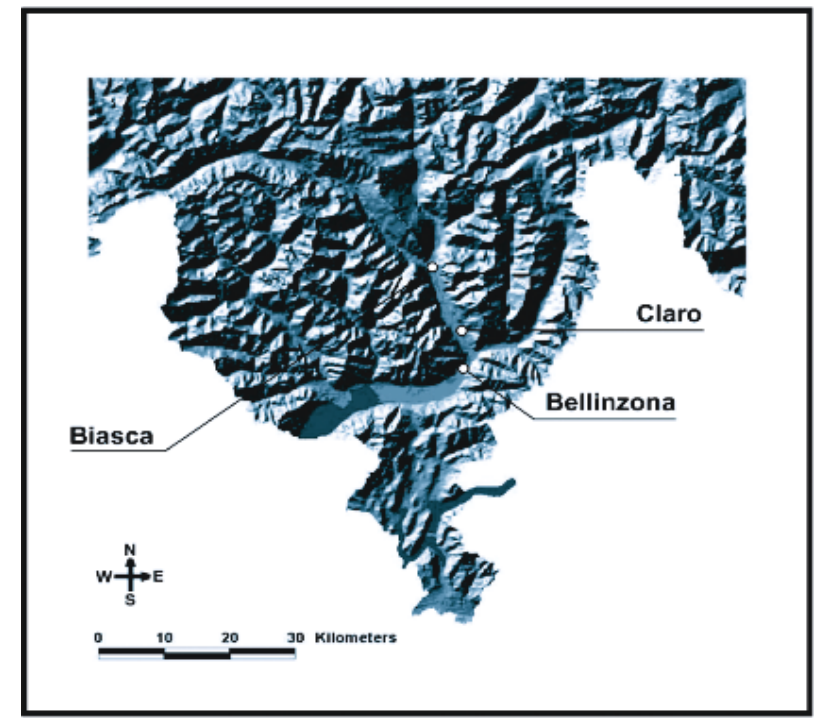

FIG. I. Topography of southern Switzerland with the Riviera valley between the towns of Biasca and Bellinzona. Cross section of surface stations (see text) runs through the valley approximately at the height of the little village of Claro.

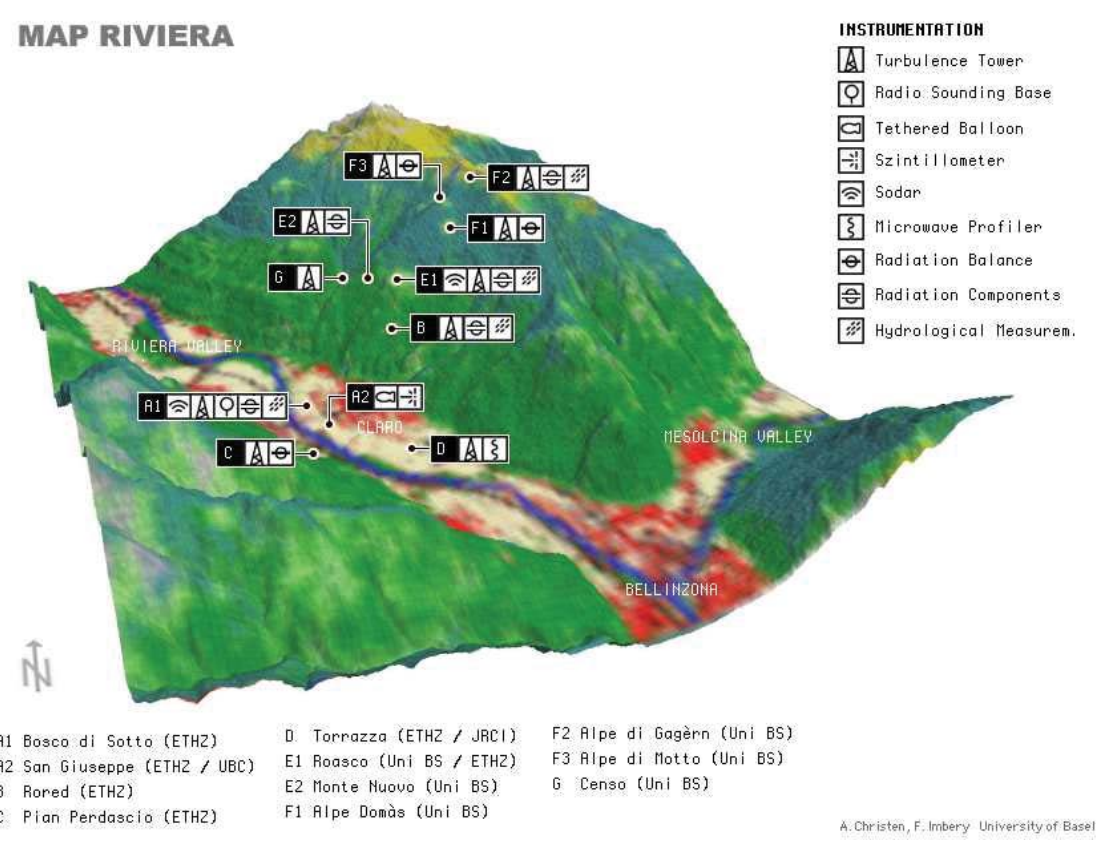

FIG. 2. Topography of the Riviera valley overlaid with land use types and the observational sites with indications of the instrumentation. The color codes for the land use are green: deciduous forest, blue-green: coniferous forest, yellow: alpine vegetation, gray: rock, white: snow, light green: meadows, light gray: agricultural land, red: settlement, light red: industrial area, blue: water, black: roads. The village of Claro can be recognized below the symbol for site $A 2$.

Continuous observations. Eleven towers were established along a southeast-northwest cross section in the Riviera valley through the village of Claro (Fig. 2) 
in order to obtain months-long observations of nearsurface turbulence and meteorological/hydrological characteristics. This setup was chosen because the cross-valley variability of flow characteristics was anticipated to be more prominent than that along the valley. Towers were located on the valley floor and the eastern slope (Fig. 2). At the principal sites, high towers with turbulence probes at several levels were erected (Table 1) and typically accommodated observations of the full radiation balance, precipitation, and standard meteorological parameters (pressure, profiles of temperature, humidity, and wind speed). Smaller towers with only one sonic anemometer level were operated mainly in regions of problematic logistics. Altogether, 20 sonic anemometers and six fast-response hygrometers continuously recorded turbulence statistics in the lowest $30 \mathrm{~m}$ of this valley's cross section for about 2 months. A field intercomparison of different sonic anemometers will briefly be introduced in the section titled Instrument intercomparison.

Detailed hydrological observations were performed at two of the principal sites (A1 and B, see Table 1). These observations included profiles of soil moisture and temperature (down to a 1.6-m depth), as well as soil heat flux, leaf wetness, and canopy pre-

TABLE I. Sites and observations in the Riviera valley: "No. hygr." stands for the number of fast-response hygrometers, Standard meteo refers to standard meteorological observations. Precip denotes precipitation, Hydro denotes hydrological observations (see text for details), and Additional obs. refers to additional observations at the respective site as described in sections Scintillometry to Sodar MTP-5: microwave temperature profiler; RS: radio sounding; TB: tethered balloon, Scint.: scintillometric measurements; $\mathrm{T}^{\prime}$ : fast response temperature measurements.

\begin{tabular}{|c|c|c|c|c|c|c|c|c|}
\hline Site & $\begin{array}{c}\text { Height } \\
\text { of tower }(m)\end{array}$ & $\begin{array}{l}\text { Turbulence } \\
\text { (No. hygr.) }\end{array}$ & $\begin{array}{l}\text { Standard } \\
\text { meteo }\end{array}$ & Radiation & Precip. & Hydro. & $\begin{array}{l}\text { Additional } \\
\text { obs. }\end{array}$ & $\begin{array}{c}\text { Surface } \\
\text { character }\end{array}$ \\
\hline Al & 28 & $\begin{array}{c}3 \text { levels } \\
\text { (2) }\end{array}$ & 6 levels & $\begin{array}{c}\text { Full } \\
\text { balance }\end{array}$ & Yes & Detailed & $\begin{array}{l}\text { MTP-5, } \\
\text { RS, } \\
\text { sodar }\end{array}$ & $\begin{array}{l}\text { Valley } \\
\text { floor, } \\
\text { mixed } \\
\text { agriculture }\end{array}$ \\
\hline $\mathrm{A} 2$ & 5 & - & $\begin{array}{c}4 \text { levels } \\
T^{\prime}\end{array}$ & - & - & & $\begin{array}{l}\text { Scint., } \\
\text { TB }\end{array}$ & As $\mathrm{Al}$ \\
\hline B & 30 & $\begin{array}{l}3 \text { levels } \\
\text { (I) }\end{array}$ & $\begin{array}{c}\text { I } \\
\text { reference }\end{array}$ & Net & Yes & Detailed & - & $\begin{array}{l}\text { Slope, } \\
\text { forest }\end{array}$ \\
\hline C & 6 & I level & - & Net & Yes & - & - & $\begin{array}{l}\text { Slope, } \\
\text { vineyard }\end{array}$ \\
\hline$D$ & 6 & $\begin{array}{l}\text { I level } \\
\text { (I) }\end{array}$ & - & - & - & - & $\begin{array}{l}\text { MTP-5, } \\
\text { scint. }\end{array}$ & $\begin{array}{l}\text { Foot of } \\
\text { slope }\end{array}$ \\
\hline EI & 12 & $\begin{array}{l}2 \text { levels } \\
\text { (I) }\end{array}$ & - & $\begin{array}{c}\text { Full } \\
\text { balance }\end{array}$ & Yes & Reduced & Sodar & $\begin{array}{l}\text { Slope, } \\
\text { meadow }\end{array}$ \\
\hline E2 & 23 & $\begin{array}{l}6 \text { levels } \\
\text { (I) }\end{array}$ & 8 levels & $\begin{array}{l}\text { Full } \\
\text { balance }\end{array}$ & - & - & 18 levels of $T^{\prime}$ & $\begin{array}{l}\text { Slope, } \\
\text { forest }\end{array}$ \\
\hline $\mathrm{FI}$ & $6 \mathrm{~m}$ & I level & 3 levels & Net & - & Some & - & $\begin{array}{c}\text { Slope, } \\
\text { sparse } \\
\text { vegetation }\end{array}$ \\
\hline F2 & II & 2 levels & 3 levels & $\begin{array}{c}\text { Full } \\
\text { balance }\end{array}$ & Yes & Some & - & $\begin{array}{l}\text { Slope, } \\
\text { shrub }\end{array}$ \\
\hline F3 & 2 & - & I level & Net & - & - & - & $\begin{array}{l}\text { Slope, } \\
\text { grass }\end{array}$ \\
\hline G & 5 & I level & 2 levels & - & - & - & I level of $T^{\prime}$ & $\begin{array}{l}\text { Slope, } \\
\text { forest }\end{array}$ \\
\hline
\end{tabular}


cipitation. At A1, profiles into the ground were obtained at various subsites with different surface cover. Together with simultaneously recorded meteorological parameters, these observations yielded an excellent opportunity to evaluate hydrological and coupled meteorological/hydrological models (Zappa et al. 2000; Carlaw et al. 2000). Additionally, soil moisture observations were obtained episodically at site E1 and in three other valleys of the region, in order to better cover the variety of surface types.

The following sections describe the additional observations that were performed during the IOPs.

Scintillometry. Due to the expected spatial variability of turbulent fluxes, it was desirable to obtain, in addition to the detailed array of point measurements from sonic anemometers, spatially averaged information on turbulence characteristics. Two small-aperture, displaced-beam scintillometers (Scintec, SLS 20) were, therefore, operated at the valley floor (site A2) and at site $\mathrm{D}$ on a gentle slope. These scintillometers yield path-weighted sensible heat flux, momentum flux, and the dissipation rate of turbulent kinetic energy over a distance between 50 and $200 \mathrm{~m}$.
There is some uncertainty surrounding the measurement principle of scintillometers in complex terrain (see Weiss et al. 2001). Large efforts were, therefore, undertaken to investigate the performance of the instruments prior to taking actual observations (Weiss et al. 1999 and our Instrument intercomparison section).

Figure 3 shows a typical example of the daily cycle of the sensible heat flux as measured simultaneously by a scintillometer at the valley floor (site A2), and a scintillometer and a sonic anemometer at the foot of the slope (site D). Generally, the difference between path-averaged and point observations at site $\mathrm{D}$ is within the respective instrument uncertainties (section on Instrument intercomparison). Daytime values of sensible heat flux on the slope (site D) are consistently larger than those observed on the valley floor (A2). Also, the valley floor site shows an earlier transition to positive heat fluxes in the morning and to negative fluxes in the afternoon. These differences reflect the variability in net radiation (Matzinger et al. 2003) due to differences in exposure and slope angle. At other sites with steeper slopes and more favorable exposure, these differences become even more pro-

\begin{tabular}{|c|c|c|c|c|c|}
\hline Date & $\begin{array}{c}\text { Flight day } \\
\text { no. }\end{array}$ & Type of day & $\begin{array}{l}\text { Flight times } \\
\text { (UTC) }\end{array}$ & $\begin{array}{c}\text { Flight } \\
\text { patterns }\end{array}$ & $\begin{array}{l}\text { Data coverage, } \\
\text { failures }\end{array}$ \\
\hline 21 Aug 1999 & 1 & \pm Convective & $\begin{array}{l}072|-103| \\
1434-1700\end{array}$ & $\begin{array}{l}\text { T-B-A-B-T, } \\
\text { T-B-A-B-T }\end{array}$ & $\begin{array}{l}\text { Full, no. } \mathrm{H}_{2} \mathrm{O} ; \\
\text { full, no. } \mathrm{H}_{2} \mathrm{O}\end{array}$ \\
\hline 22 Aug 1999 & 2 & \pm Convective & $\begin{array}{l}0736-1010 \\
1136-1554\end{array}$ & $\begin{array}{c}\text { T-A-B-T, } \\
\text { T-B-A-B-A-B-T }\end{array}$ & $\begin{array}{l}\text { No wind and } \\
\mathrm{H}_{2} \mathrm{O} \\
\text { full, no } \mathrm{H}_{2} \mathrm{O}\end{array}$ \\
\hline 25 Aug 1999 & 3 & Convective & $\begin{array}{l}\text { 0649-0942, } \\
|||| 2-154 \mid\end{array}$ & $\begin{array}{l}\text { T-A-B-A-B-T, } \\
\text { T-B-A-B-A-B-T }\end{array}$ & $\begin{array}{l}\text { Full, } \\
\text { full }\end{array}$ \\
\hline 21 Sep 1999 & 4 & Mixed & $\begin{array}{l}0716-0905 \\
1117-1510\end{array}$ & $\begin{array}{c}\text { T-B-A-B, } \\
\text { T-B-A-B-A-B-A-T }\end{array}$ & $\begin{array}{l}\text { Full, } \\
\text { no wind }\end{array}$ \\
\hline 22 Sep 1999 & 5 & Mechanical & $\begin{array}{l}0658-0925 \\
1 \mid 15-1302\end{array}$ & $\begin{array}{l}\text { T-A-B-A-T-B, } \\
\text { T-B-A-B-A-B }\end{array}$ & $\begin{array}{c}\text { Full, } \\
\text { low resolution wind }\end{array}$ \\
\hline $28 \mathrm{Sep}$ & 6 & $\begin{array}{l}\text { Mechanical, } \\
\text { transition from } \\
\text { rainy period }\end{array}$ & $|202-16| 4$ & T-B-A-B-A-B-T & $\begin{array}{c}\text { Full, } \mathrm{H}_{2} \mathrm{O} \text { low } \\
\text { quality }\end{array}$ \\
\hline 29 Sep 1999 & 7 & $\begin{array}{c}\text { Convective } \\
\text { morning, } \\
\text { mixed afternoon }\end{array}$ & $\begin{array}{l}0722-0945 \\
1156-1553\end{array}$ & $\begin{array}{c}\text { T-B-A-B-T, } \\
\text { T-B-A-B-A-B-T }\end{array}$ & $\begin{array}{l}\text { Full, } \\
\text { full }\end{array}$ \\
\hline I Oct 1999 & 8 & Convective & $1033-1409$ & T-B-A-B-A-B-T & Full \\
\hline
\end{tabular}




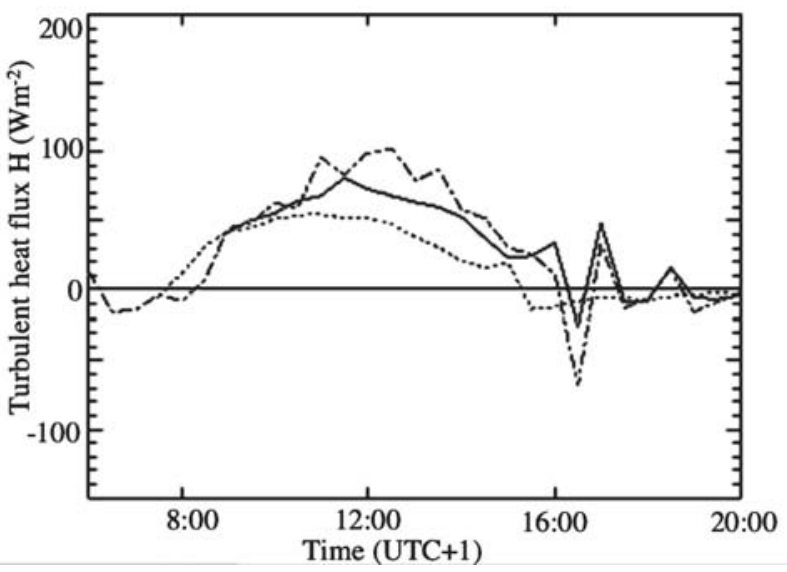

Fig. 3. Time series of turbulent sensible heat flux $(H)$ as measured by scintillometry on the valley floor (site A2, dotted line) and on lightly sloping terrain (site D, solid line) on I Oct 1999. Dashed line: Sonic anemometer observation at site $D$. nounced (De Wekker et al. 2004, see also our section on Surface energy balance on a slope).

Radio soundings. Radiosondes were launched from the valley floor (site $\mathrm{A} 1$ ) at 3-hourly intervals during flight days, starting at 0600 and ending at 2400 UTC. In addition, on the day before a flight day, two soundings at 1200 and 1800 UTC were launched to obtain some detail of the developing situation. For all the R-IOP2 soundings, release times were $1 \mathrm{~h}$ earlier (so that the sonde would reach the tropopause around 0000, 0600, 1200 , and 1800 UTC). A Vaisala MW11 receiving system was employed using RS80 sondes, which are equipped with standard pan-tilt unit (PTU) sensors and an 8-channel digital GPS receiver. The accuracy of the raw data is $0.5 \mathrm{hPa}$ (pressure), $0.2 \mathrm{~K}$ (temperature), $3 \%$ (relative humidity), and $0.5 \mathrm{~m} \mathrm{~s}^{-1}$ (wind speed). The sounding system has a vertical range of over $20 \mathrm{~km}$. However, in about $50 \%$ of the soundings the radio signal was lost before the sonde reached the tropopause.

Passive microwave temperature profiler. A meteorological temperature profiler (Kipp \& Zonen, MTP-5) was operated at the valley floor (site Al) during R-IOP1, and closer to the eastern slope of the Riviera valley (site $\mathrm{D}$ ) during R-IOP2. The MTP-5 is a passive microwave sensor, which allows determination of air temperature profiles from the ground up to $600 \mathrm{~m}$, at a vertical resolution of $50 \mathrm{~m}$ and a temporal resolution of $5 \mathrm{~min}$. The instrument senses a cone of about $500 \mathrm{~m}$ in length, yielding a "profile" of the air temperature with some spatial averaging (Kadygrov and Pick 1998). This instrument sensed the daily evolution of static stability in the lower part of the valley atmosphere at high temporal resolution. Because the MTP-5 is a relatively recently developed 
instrument, its collocation with the radio sounding system at site $\mathrm{A} 1$ during R-IOP1 was exploited for a systematic intercomparison.

As an example of data from the MTP-5, a time-height cross section of temperature in the lowest $600 \mathrm{~m}$ at site A1 in the Riviera valley is presented (Fig. 4). The daily cycle is very pronounced with the expected well-mixed layer within the observed lowest $600 \mathrm{~m}$ (see also Fig. 9) and a stable near-surface layer during the night. The maximum temperature difference across the inversion (9.8 K) was observed at 0555 LST (Local Standard Time, corresponds to UTC + 2) 6 October 1999 at a height of $350 \mathrm{~m}$. Continuous measurements at 5-min temporal resolution yield information on the very quick transition between nearsurface nocturnal and daytime temperature regimes. Within about $20 \mathrm{~min}$ of sunrise or sunset (Weber 2000, unpublished Msc Thesis) the stable (unstable) layer close to the surface is eroded and the lowest $50 \mathrm{~m}$ of the valley atmosphere changes stability. Figure 5 shows an example of the sunrise transition on 24 September. The newly developed morning unstable layer near the surface is topped by an approximately neutral region, while in the evening the transition directly leads to an elevated inversion.

Tethered balloon sounding. Profiles of temperature, humidity, wind speed, and direction were taken at site A2 on the valley floor by operating an Atmospheric Instrumentation Research, Inc. (AIR), tethersonde (type TS-3A-SPH). Due to restrictions imposed by local air traffic control authorities, these ascents could only be performed on flight days during R-IOP2. A typical ascent-descent cycle took about $30 \mathrm{~min}$ and reached a maximum height of $800 \mathrm{~m}$ above the valley floor. In combination with other "profiling systems," the tethersonde data allow for a detailed investigation of the valley atmosphere's spatial structure.

Sodar. Two monostatic flat-array sodars (Scintec, FAS64) were situated at sites A1 and E1. Due to noise pollution these instruments could not be operated continuously for day-and-night periods during flight days. In addition, the sodar at site A1 exhibited some technical problems, which inhibited operation most of the time. The instrument at site E1 was operated with a height-dependent vertical resolution $(10 \mathrm{~m}$ near the ground, and coarser with increasing height) and a temporal resolution of 20-30 min.

Research flights. Research flights were performed with an instrumented light aircraft (Neininger et al. 2001) operated by MetAir for a total of eight flight days. The aircraft is typically operated at a cruising speed of $200 \mathrm{~km} \mathrm{~h}^{-1}$ and has an endurance of $4-5 \mathrm{~h}$. The aircraft measured standard meteorological variables with a high enough sampling rate to allow for the derivation of turbulence statistics (for details on the instrumentation see the MAP-Riviera Web site). Precise locations and height were continuously recorded for later mapping. In addition to meteorological parameters, aerosol concentrations and some trace gas concentrations were measured as parameters that can be used to identify the origin of air masses and transport processes. During some flights a downward-looking IR camera was employed to map the surface (radiation) temperature field.

A flight day consisted of one of the following: a morning flight, an afternoon flight, or both. Generally, a flight started and ended with a profile flown up to about $4000 \mathrm{~m}$ or to the ceiling height (pattern T). In between, a succession of two different flight patterns was flown:

i) pattern A: valley traverses at different heights (Fig. 6a) yielding a quasi-stationary valley cross section of mean flow and turbulence characteristics; and

ii) pattern B: along-valley flight legs close to the slopes and in the center of the valley at different heights yielding a three-dimensional picture of the valley atmosphere (Fig. 6b). 


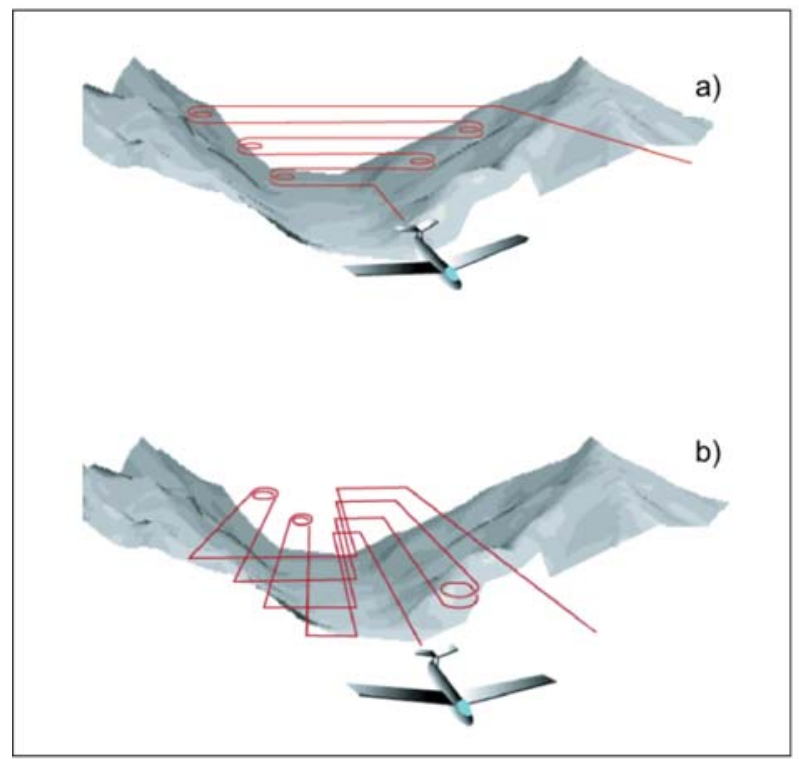

FIG. 6. Flight patterns of the research flight during the MAP Riviera field campaign (a) Cross-valley flight legs (pattern A) and (b) along-valley flight legs (pattern B).

A typical flight then consisted of a succession of flight patterns such as T-A-B-A-B - T, with care taken to ensure that flight legs were flown in similar locations on the various days. Depending on the weather conditions and other considerations, longer and shorter sequences were flown during the eight flight days.

Flight days were selected such that days with distinctly different boundary layer characteristics were captured, exhibiting the following:

a) "fully convective" conditions (weak synoptic forcing, clear sky, development of a valley wind system),

b) "fully mechanical" conditions (strong synoptic forcing, overcast), and

c) "mixed" conditions or, in boundary layer terminology, conditions of forced convection.

A summary of the eight flight days is given (Table 2), where the number of different day types can be found. The majority (usually more than $95 \%$ ) of continuous observations (see similarly titled section) were active during a flight day. Furthermore, all the "additional observations systems" (Table 3) were operating at least during the periods of actual flights. In total, 14 flights were made, with approximately $45 \mathrm{~h}$ of data.

Tracer releases. The simulation of pollutant dispersion in complex terrain is notoriously difficult due to complicated flow and turbulence fields in such environments. The detailed meteorological and turbulence data, as obtained in the present project, yielded an excellent background for testing and possibly improving currently available dispersion models for complex terrain. Two release experiments (on 29 September and 6 October) were carried out during the field phase of the project. Both of these days were dominated by clear skies with a valley wind developing, thereby simplifying planning of sampler locations.

The tracer was released from a point located near the village of Claro (point "R" in Fig. 7) at 1400 LST for both cases. The release height was $5 \mathrm{~m}$ AGL. The actual release lasted for $25 \mathrm{~min}$ and was made at a constant rate of $2 \mathrm{~g} \mathrm{~s}^{-1}$. The tracer, belonging to the family of cyclic perfluorocarbons (PFCs), was perfluorodymethylcyclohexane (PP3; see Girardi et al. 1998). These substances are environmentally benign, very stable, nontoxic, insensitive to rain washout, and are detectable by chemical analysis at extremely low concentrations $\left(10^{-16} \mathrm{v} / \mathrm{v}\right.$, i.e., $\left.1.5 \mathrm{pg} \mathrm{m}^{-3}\right)$.

Ground-level samplers were deployed with positions dictated by accessibility, with 6 along the valley axis over
TABLE 3. Details of the additional observations, $H$ and $M$ denote the turbulent fluxes of sensible heat and momentum, respectively, " $\varepsilon$ " = dissipation rate of turbulent kinetic energy, $T=$ temperature, $\mathbf{R H}=$ relative humidity, WS $=$ wind speed, and WD $=$ wind direction.

\begin{tabular}{|c|c|c|c|}
\hline Instrument & Site(s) & Variables & Duration \\
\hline $\begin{array}{l}\text { Scintillometer, } \\
\text { SLS20 }\end{array}$ & $A 2$ and $D$ & $\begin{array}{c}H, M, \varepsilon \text { (path- } \\
\text { weighted averages) }\end{array}$ & $\begin{array}{l}\text { All flight days + } \\
\text { additional days } \\
\text { during R-IOPs }\end{array}$ \\
\hline $\begin{array}{l}\text { Temperature profiler, } \\
\text { MTP-5 }\end{array}$ & Al or D & Profile of $T$ & $\begin{array}{l}\text { R-IOPI and R-IOP2 } \\
\text { (continuously) }\end{array}$ \\
\hline $\begin{array}{l}\text { Radio sounding, } \\
\text { MWII }\end{array}$ & $\mathrm{Al}$ & $\begin{array}{l}\text { Profiles of } T, R H, \\
\text { WS, and WD }\end{array}$ & All flight days \\
\hline Tethered balloon & $\mathrm{A} 2$ & $\begin{array}{l}\text { Profiles of } T, \mathrm{RH} \text {, } \\
\text { WS, and WD }\end{array}$ & $\begin{array}{l}\text { All flight days } \\
\text { during R-IOP2 }\end{array}$ \\
\hline Sodar & $(\mathrm{Al})$ and $\mathrm{EI}$ & Profile of WS & $\begin{array}{l}\text { Some periods during } \\
\text { selected flight days }\end{array}$ \\
\hline
\end{tabular}


a distance of roughly $10 \mathrm{~km}$ (Fig. 7) and 10 along the eastern slope. Figure 8 shows that the sampler positions allowed for the investigation of plume spread along the valley slope. Samplers along the valley floor were equipped with eight bags per sampler, sampling air over 30-min intervals. Samplers distributed on the slope were equipped with tubes. Each sampler contains 12 tubes programed to sequentially sample for 20 min (4-h sampling period).

The three panels of Fig. 8 show the time evolution of the tracer mixing ratio $\left(10^{-15} \mathrm{l} / \mathrm{l}=\mathrm{fl} / \mathrm{l}\right)$ as measured

during the two tracer releases at selected sampler sites. The two upper panels give the tracer mixing ratio measured by samplers on the eastern slope of the valley. The lower panel gives the time evolution of the tracer mixing ratio measured along the valley during the first release. No tracer was detected at the valley floor during the second release. The three panels reveal that the sampling network nicely detected the plume's passage. During the first release (Fig. 8, top) the tracer cloud is confined below $1000 \mathrm{~m}$ ASL and arrives at different times at the lower samplers. During the second release, on the other hand, the tracer peak is simultaneously detected by all samplers within the first three 20-min sampling periods (Fig. 8, middle). The mixing ratio then decreases at a constant rate at all altitudes. Along the valley axis (Fig. 8, bottom), the arrival of the peak mixing ratio is delayed for larger travel distances. The first three samplers exhibit a clear peak, while those at some kilometers distance (cf. positions in Fig. 7) show an approximately constant concentration after the arrival of the plume. This suggests a relatively well-mixed lower portion of the valley atmosphere as was found on other days with a well-developed valley wind system (see Fig. 9).

INSTRUMENT INTERCOMPARISON. The MAP Riviera project was mainly devoted to the investigation of spatial variability of turbulence statistics in highly complex terrain and its relation to mean flow. This was achieved by using a large number of instruments of a similar type, such as sonic anemometers, and by combining different observational tech- niques at different sites. It was, therefore, of major importance to assess the relative performance of various instruments prior to or during the field campaign. It is not within the scope of this overview to present all of the corresponding efforts in detail, but a brief summary of some of the most important aspects is provided as follows.

Sonic anemometer intercomparison. During a week in early July 1999, 19 sonic anemometers of five different types were deployed on a small airfield with homogeneous surface conditions. Details of the setup and procedures can be found in Christen et al. (2000, 2001). The sonic anemometers were found to compare reasonably well in the derived turbulence statistics (Table 4). Those statistics that include the temperature are generally less reliable than those with only wind components. Furthermore, the relative error of the wind statistics (and, more so, those including temperature) increases with smaller absolute wind speed. Overall, it was concluded that the relative accuracy of the instruments was good enough to detect significant differences in turbulence statistics in the actual field study.

Scintillometers. Two displaced-beam scintillometers (Scintec, SLS 20) were compared to sonic anemometers, and with each other, in the same prefield campaign described above (Weiss 2002). Excellent correspondence was found between the two scintillometers with correlation coefficients of $r_{M}=0.94$ (momentum flux $M$ ) and of $r_{H}=0.99$ (sensible heat 

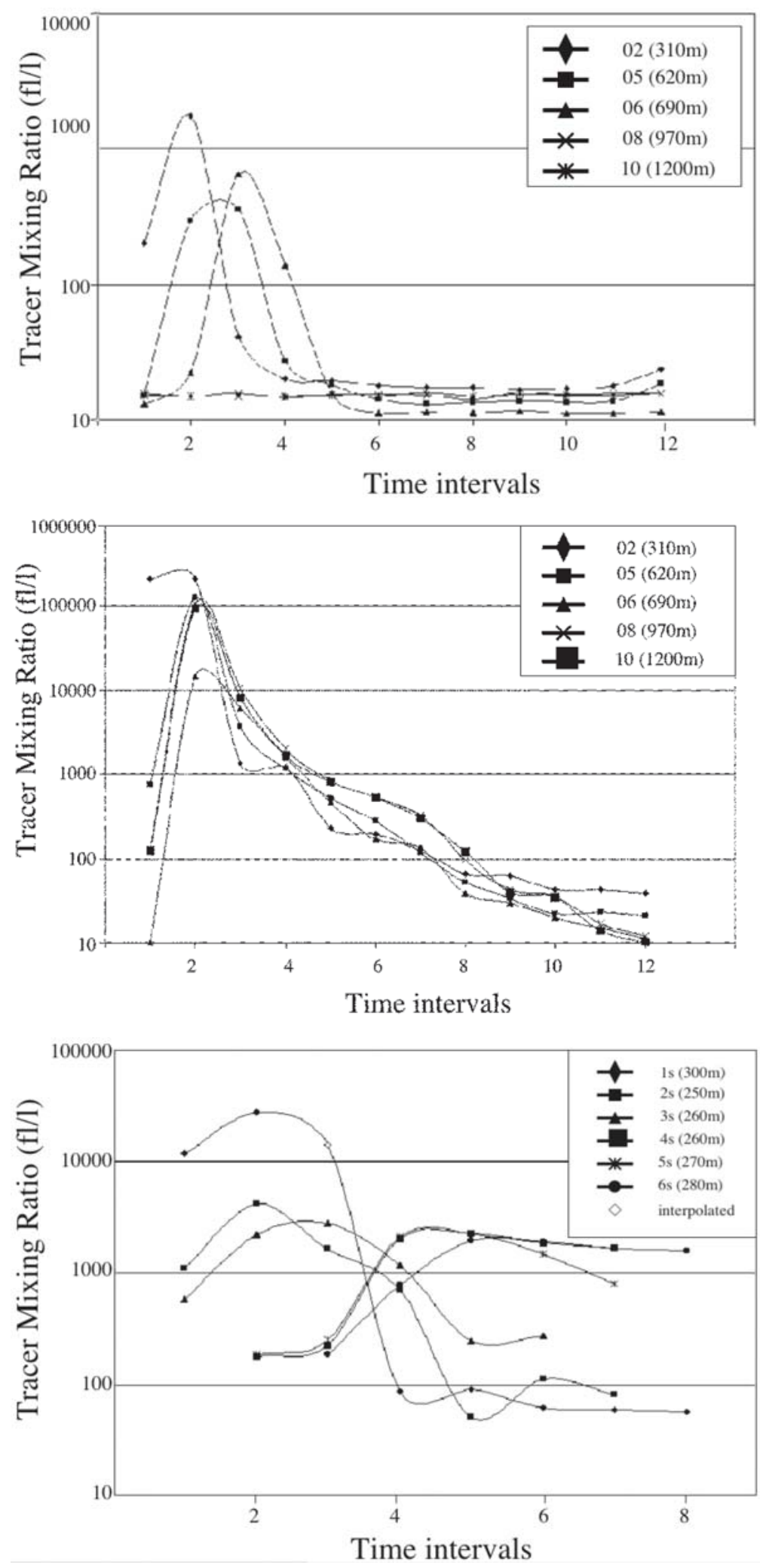

Fig. 8. Tracer concentrations at the various sampling points (as indicated in the inlets, cf. Fig. 7). The sampling time interval of the samplers along the valley (bottom panel) was $30 \mathrm{~min}$., that on the slope amounted to $20 \mathrm{~min}$. flux $H$ ), and rms differences of about $0.02 \mathrm{~N} \mathrm{~m}^{-2}$ (momentum flux) and less than $10 \mathrm{~W} \mathrm{~m}^{-2}$ (heat flux). This is considerably less than the scatter among the various sonic anemometers. Also, the comparison between sonic anemometers on the one hand and scintillometers on the other was satisfying: $\mathrm{rms}_{H}=12 \mathrm{~W} \mathrm{~m}^{-2}$ and $\mathrm{rms}_{M}=0.04 \mathrm{~N} \mathrm{~m}^{-2}$, respectively. A more detailed analysis of the dataset revealed that the correspondence of turbulent fluxes was very good for clearly stable and unstable conditions, but was less so for the momentum flux under near-neutral conditions (Weiss 2002). An additional experiment that addressed the question of measurement height in complex topography in connection with scintillometers is summarized in the Sidebar.

MTP-5 versus radio soundings. Data from the passive microwave temperature profiler MTP-5 were compared to temperature profiles from simultaneously launched radiosondes at the same site (A1), yielding a total of 52 profiles for comparison. Rms differences between data from the two systems were smaller than $1.0 \mathrm{~K}$ everywhere (Kadygrov et al. 2001), regardless of the shape of the profile. When selecting only closely linear profiles, the rms difference was $0.39 \mathrm{~K}$, while those profiles with a distinct inversion exhibited an rms difference of $0.47 \mathrm{~K}$. The largest differences between the two systems were observed for "mixed profiles." In most of the compared profiles the temperature gradients, that is, the static stability, were closely comparable. The favorable correspondence between the data from the two systems allows a combination of their respective advantages for investigation of temperature structure in the Riviera valley. While the MTP- 5 has a limited height range $(600 \mathrm{~m})$ but a high temporal resolution (5 min), the radiosondes can reach higher al- 
TABLE 4. Typical instrument-to-instrument uncertainty (rms differences) for turbulence statistics as derived from the field intercomparison on an airfield in southern Switzerland in Jul 1999. "Outliers" refers to three instruments that were found to have problems in one or more of the measured variables. Statistics are based on about $\mathbf{4 0}$ half-hourly averages under optimal conditions (fetch, threshold requirements).

\begin{tabular}{|l|c|c|c|c|c|c|}
\hline & $\bar{u}\left(\mathrm{~m} \mathrm{~s}^{-1}\right)$ & $\sigma_{u, v}\left(\mathrm{~m} \mathrm{~s}^{-1}\right)$ & $\sigma_{\mathrm{w}}\left(\mathrm{m} \mathrm{s}^{-1}\right)$ & $\sigma_{\theta}(\mathbf{K})$ & $\mathbf{u}_{*}\left(\mathrm{~m} \mathrm{~s}^{-1}\right)$ & $\overline{w^{\prime} \theta^{\prime}}\left(\mathrm{K} \mathrm{m} \mathrm{s}^{-1}\right)$ \\
\hline $\begin{array}{l}\text { Maximum error of } \\
\text { good instruments (\%) }\end{array}$ & 2 & 4 & 8 & 15 & 11 & 15 \\
\hline Outliers (\%) & 14 & 14 & 18 & 27 & 27 & 89 \\
\hline
\end{tabular}

titudes but were launched only every $3 \mathrm{~h}$ during the flight days.

\section{RESEARCH OBJECTIVES AND PRELIMI- NARY RESULTS. Here, we summarize specific research objectives of the Riviera project. Rather than simply listing research objectives we will illustrate them using data from the field observations.}

Turbulence structure in an alpine valley. Due to the sparse (essentially nonexistent) observational evidence concerning the turbulence structure in an alpine valley, a first goal of the MAP-Riviera project must consist of establishing a phenomenological picture of turbulence in such an environment. This provides a basis for exploring specific exchange mechanisms and also serves as a basic picture, on which results from numerical models can be examined. The approach consists in first defining characteristic flow regimes similar to those in Table 2 (Andretta et al. 2001). For each of these flow regimes background boundary layer structure in the valley is established with reference to earlier work (e.g., Whiteman 2000).

Figure 9 depicts the profiles of wind direction and potential temperature on a clear summer day with weak synoptic forcing. Wind direction exhibits valley wind characteristics with down-valley wind (about $\left.340^{\circ}\right)$ during the night and up-valley wind $\left(160^{\circ}\right)$ during the day. Valley wind depth reaches about $1600 \mathrm{~m}$ ASL during night with a transition to geostrophic

\section{MEASUREMENT HEIGHT FOR A SCINTILLOMETER BEAM}

Scintillometers use information on the spread of a laser beam over a distance of some $100 \mathrm{~m}$ to derive spatially averaged turbulence characteristics. In this algorithm the height of observation plays an important role, which is, obviously, difficult to determine in highly complex terrain. To address this problem, an experiment was performed on the occasion of the instrument intercomparison (see similarly titled section). Thereby, a scintillometer was set up with an inclined path, with the transmitter at a height of $1.35 \mathrm{~m}$ and the receiver at a height of $2.15 \mathrm{~m}$, with the resulting mean height of the laser beam at $1.75 \mathrm{~m}$. This latter height corresponded to that of a set of sonic anemometers $(1.8 \mathrm{~m})$. Figure SB I shows the resulting scatterplots of turbulent fluxes from this experiment. The root-mean-square differences for sensible heat and momentum fluxes amounted to $16 \mathrm{~W} \mathrm{~m}^{-2}$ and $0.02 \mathrm{~N} \mathrm{~m}^{-2}$, respectively, and were, thus, comparable to those for experiments with the leveled scintillometers (section titled Instrument intercomparison) under similar atmospheric conditions. These results indicate that over uneven terrain an average height of the laser beam determined over the path of the scintillometer may be a useful choice for the "measuring height."

FIG. SBI. Comparison of (top) momentum flux and (bottom) sensible heat flux from an inclined scintillometer (see text) to an average of five collocated sonic anemometer measurements.
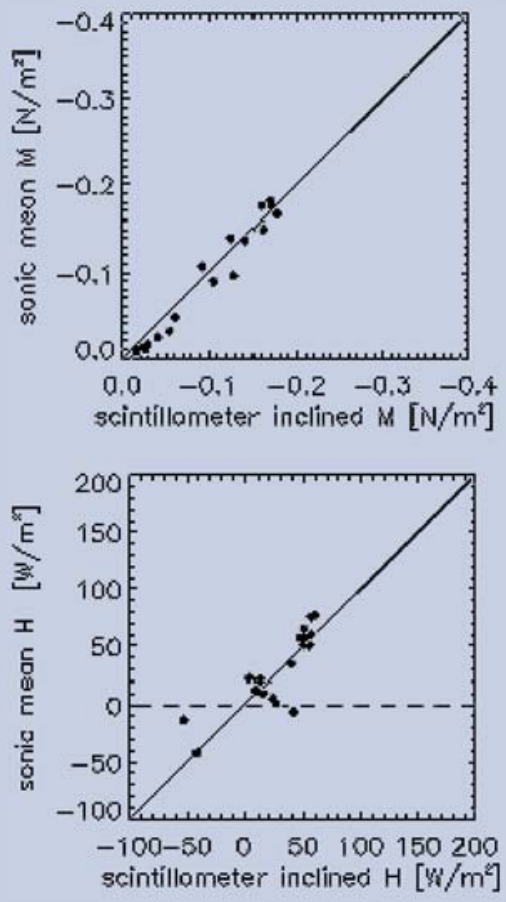

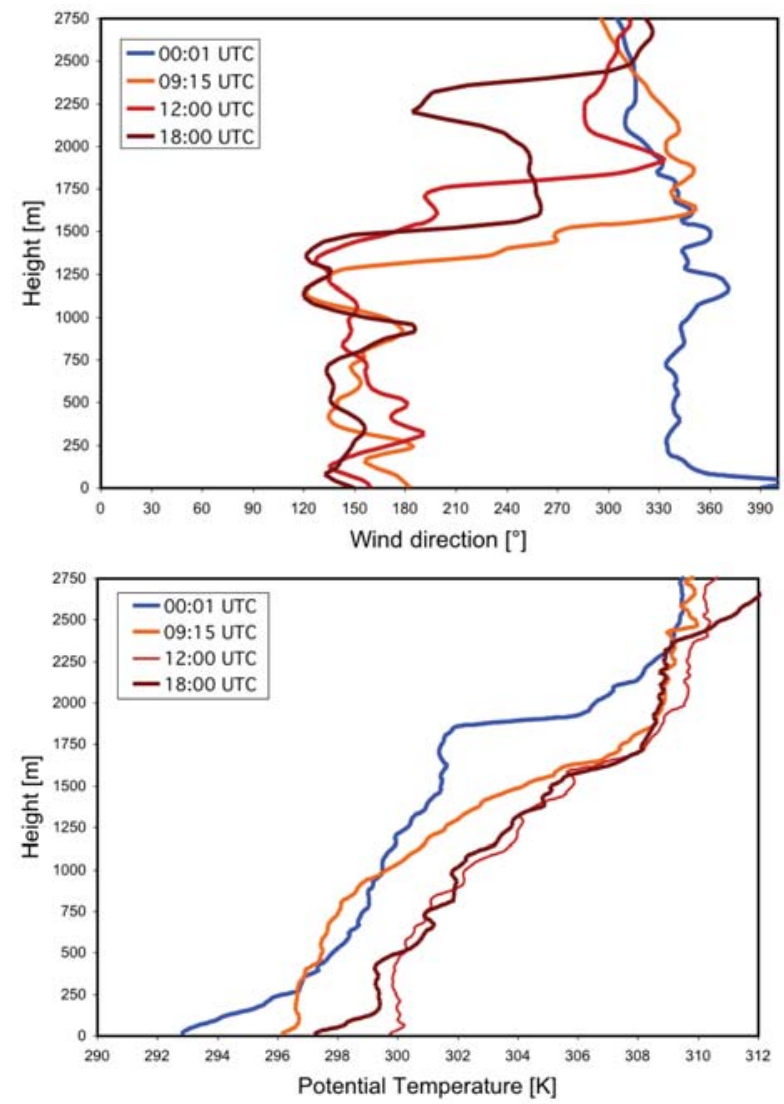

FIG. 9. Profiles of (top) potential temperature and (bottom) wind direction at site AI in the Riviera valley on 25 Aug 1999. Release times are indicated in the inlets.

wind direction $\left(300^{\circ}\right)$ higher up. This latter is reached above the mean crest height (roughly $2000 \mathrm{~m} \mathrm{ASL}$ ). During the day valley wind direction extends up to about $1600 \mathrm{~m}$ ASL. In the transition layer toward the geostrophic wind direction some indications of return flow can be observed.

Potential temperature profiles show a distinct three- or four-layer structure. During nighttime, a strongly stable layer a few hundred meters deep is topped by a less stable layer up to $2000 \mathrm{~m}$ ASL. A sharp transition then occurs toward the modestly stable lower free troposphere. For some ascents during the night (not shown) this transition occurs over a layer of a few hundred meters depth. The daytime valley atmosphere is well mixed in the lowest $700 \mathrm{~m}$. Higher up there is a deep stable layer $(d \Theta / d z \approx$ $0.006 \mathrm{~K} \mathrm{~m}^{-1}$ ) up to about $1600 \mathrm{~m}$ ASL where a sharp transition occurs. There is some indication of a fourth layer between 1600 and $2000 \mathrm{~m}$ ASL, that is, the mean crest height.

The observed daytime potential temperature profiles do not support the inversion breakup hypothesis of Whiteman (1990), which leads to a well-mixed layer in the entire valley atmosphere for larger valleys in the afternoon. However, it does bear some similarity to a multilayer structure observed in a neighboring valley during VOTALP (Furger et al. 2000) or to the observations of Kuwagata and Kimura (1995) who describe a two-layer structure related to a cross-valley circulation.

From these observations it appears that dynamic and thermodynamic structures of the valley flow do not necessarily correspond. During nighttime the layer between approximately $1600 \mathrm{~m}$ ASL and crest height is characterized by a transition in wind direction, but no clear signal can be seen in the stratification. During daytime, on the other hand, the valley wind layer (up to about $1600 \mathrm{~m} \mathrm{ASL}$ ) is well mixed up to a few hundred meters and stably stratified in its upper part.

Calanca et al. (2000) presented a preliminary analysis of turbulence structure in the afternoon valley atmosphere of 25 August 1999. As an example, we show the kinematic turbulent momentum flux as obtained from airborne observations on a cross section through the Riviera valley collocated with the surface towers (Fig. 10). In a relatively shallow band a few hundred meters deep, the turbulent flux is observed to be substantially different from zero. Comparison to the noon sounding of the same day (Fig. 9) indicates that this turbulent layer roughly corresponds to the well-mixed lowest portion of the valley atmosphere. Nonzero turbulent momentum flux is confined to the layer of the valley wind (Fig. 9). The largest momentum fluxes are found near the eastern slope, and near the center of the valley atmosphere, that is, somewhat west of the observed "core" of the valley wind on that day (Calanca et al. 2000).

Over all, the turbulence structure is found to exhibit large spatial variability that is largely driven by the differences in the surface energy balance (section titled Surface energy balance on a slope) at the valley floor and the two slopes. Other flight days (not shown) exhibit a quite different structure in the valley atmosphere's turbulence structure, and its relation to the mean flow field remains to be evaluated in detail.

It is one of the primary objectives of the Riviera project to investigate to what extent high-resolution numerical models are capable of reproducing not only observed mean flow fields, but also the turbulence structure of an alpine valley. First simulations using the Regional Atmospheric Modeling System (RAMS; De Wekker et al. 2002) show a quite favorable correspondence in the mean variables (potential temperature, wind speed components) for one case study. The turbulent surface fluxes, on the other hand, exhibit 
substantial differences between the model and observation (De Wekker et al. 2002). The investigation of turbulent exchange processes, as outlined in the next section, will allow us to evaluate the corresponding parameterizations in numerical models in the future.

Turbulent exchange processes of heat, moisture, and momentum. To investigate, and possibly improve on, turbulent exchange parameterizations in numerical models the underlying processes must first be known and understood. Of primary importance in this respect is the surface exchange of heat, momentum, and moisture for the various characteristic surfaces (valley floor, sunlit and shaded slopes). One major challenge in this respect is the simultaneous occurrence of slope effects, surface inhomogeneity, and the presence of a roughness sublayer due to the variable nature of the slope surface (Rotach 1995). However, this is the normal situation in a real valley and the present dataset provides an excellent basis for addressing these questions. Mechanisms of turbulent exchange within the canopy and the roughness sublayer on the slope have been investigated in detail by Van Gorsel et al. (2003, 2001, 2000).

Andretta et al. (2001, 2000) have investigated the interaction between the valley wind and slope wind systems on clear summer days with weak synoptic forcing. While turbulent moment transport at the valley floor (site A1) is dominated by the along-wind component of Reynolds stress $\left(\overline{u^{\prime} w^{\prime}}\right)$, as is the case over flat, horizontally homogeneous terrain, a substantial contribution of lateral shear stress $\left(\overline{v^{\prime} w^{\prime}}\right)$ is observed at the slope site B and at other slope sites (van Gorsel et al. 2003). This is due to directional shear introduced through the transition from the near-surface up-slope
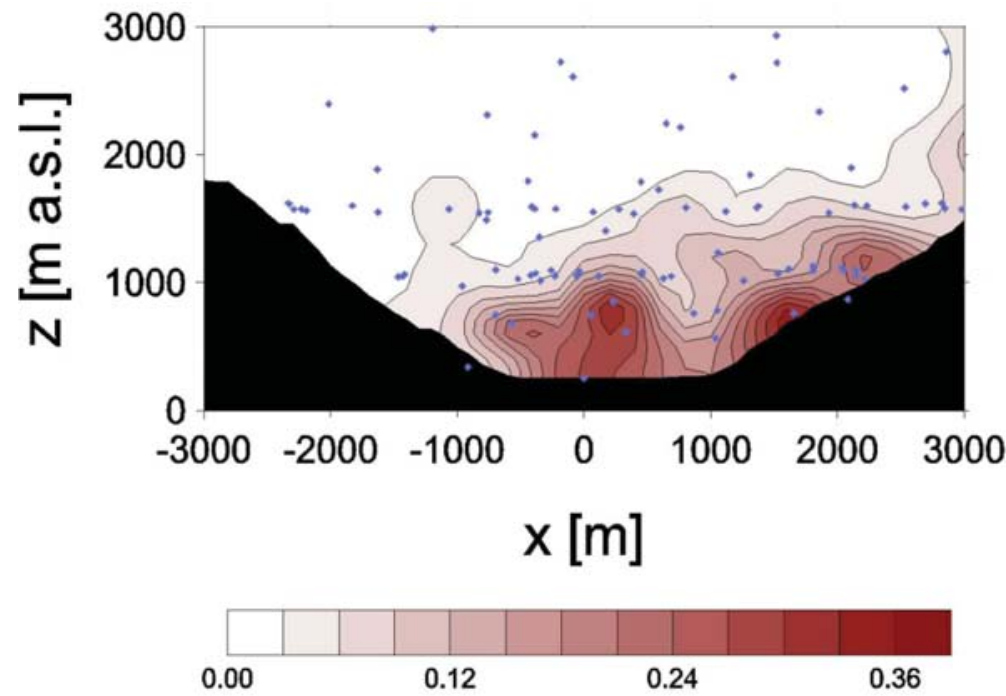

FIG. I0. Kinematic turbulent momentum fluxes on a cross section through the Riviera valley. The data are 2-h averages from the afternoon flight of 25 Aug 1999 ( I 200-| 400 UTC, flight day 3, Table 2). The light blue diamonds indicate the position of data points from which the fields are interpolated (if below the terrain: irregularity of the terrain mask). The surface towers are indicated by only one square even if three or more levels are available. Units are $\mathrm{m}^{2} \mathrm{~s}^{-2}$.

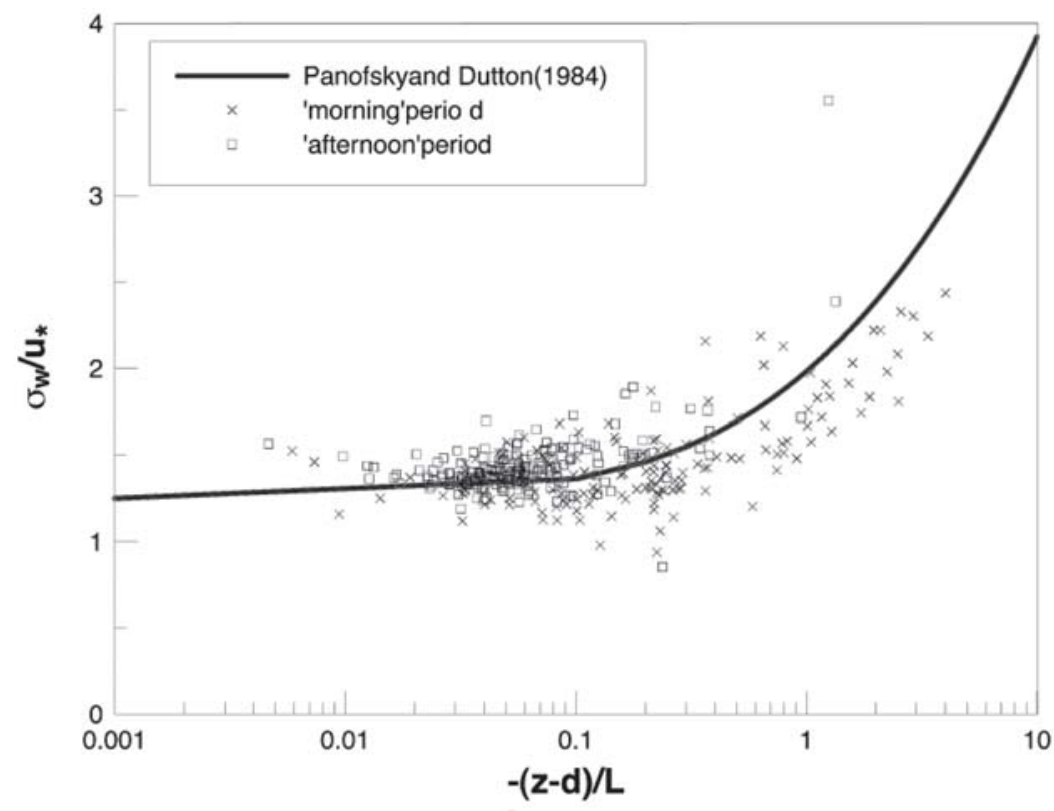

FIG. I I. Scaled vertical velocity fluctuations at site B (see Fig. 2). Observations from the upper two levels at 24 and $30 \mathrm{~m}$ ASL, respectively. The scaling velocity is derived from the local observations of longitudinal and lateral Reynolds stress components (see text).

wind to a valley wind regime (up valley) at the higher levels of observation. This raises the question of whether the conventional definition of a friction velocity $u_{*}=\left(\overline{u^{\prime} w^{\prime 2}}+\overline{v^{\prime} w^{\prime 2}}\right)^{1 / 4}$ can be retained for such a complicated flow. Figure 11 shows some preliminary 
evidence that indeed the sum of (vertical) frictional and directional shear stresses determine a characteristic local velocity scale. Andretta et al. (2001) show that using the longitudinal stress component alone to derive a "friction velocity" (what makes sense only over homogeneous surfaces, when $\overline{v^{\prime} w^{\prime}}$ vanishes) leads to markedly inferior results (not shown). In Fig. 11, a distinction is made between "morning" and "afternoon" periods because Andretta et al. (2000) found these periods to exhibit distinct vertical profiles of Reynolds stress components. However, the locally scaled vertical velocity seems to be insensitive to this difference.

Conventional surface exchange schemes employed in numerical models rely on the Monin-Obukhov similarity theory to determine momentum fluxes from the mean wind profile and, thus, do not incorporate the contribution of directional shear. They can, therefore, be expected to underestimate the friction velocity and, hence, mechanical turbulence. A more detailed analysis is needed in future investigations of this problem.

Surface energy balance on a slope. Clearly, the radiation balance in a valley and particularly on a slope is different from that on a flat surface (Whiteman et al. 1989a). This is due to both shortwave and longwave contributions, which are influenced by surrounding topography (Matzinger et al. 2003). While the former exhibits temporal variation according to obstruction of direct solar radiation, incoming longwave radiation is not only determined by temperature and density profiles in the atmosphere, but is also modified by emission from nearby surfaces. In consequence, the energy balance on a slope is different from that on a flat surface and a position-specific energy partitioning can be expected at various valley locations.

Figure 12 compares components of the energy balance at the valley floor site (A1) to that on the slope for a selection of 15 "valley wind days," that is, clear days with weak synoptic forcing (see Andretta et al. 2001 for a definition). At site A1 the sum of sensible, latent, and ground heat fluxes makes up about half the available radiative energy, and this is observed on each of the individual days as well as in the average over all valley wind days. Similar failure of closure of the energy balance has been observed at other, even less complicated, sites (e.g., Vogt et al. 1996) provided that all of the components were directly measured. Clearly, if the energy balance is determined using, for example, the Bowen ratio method, it will be closed by definition even if the measurements are taken over highly complex terrain (e.g., Whiteman et al. 1989b).

The consistent gap between available radiative energy and turbulent and ground heat fluxes cannot be attributed to measurement errors alone in the present case. Although the various contributions to
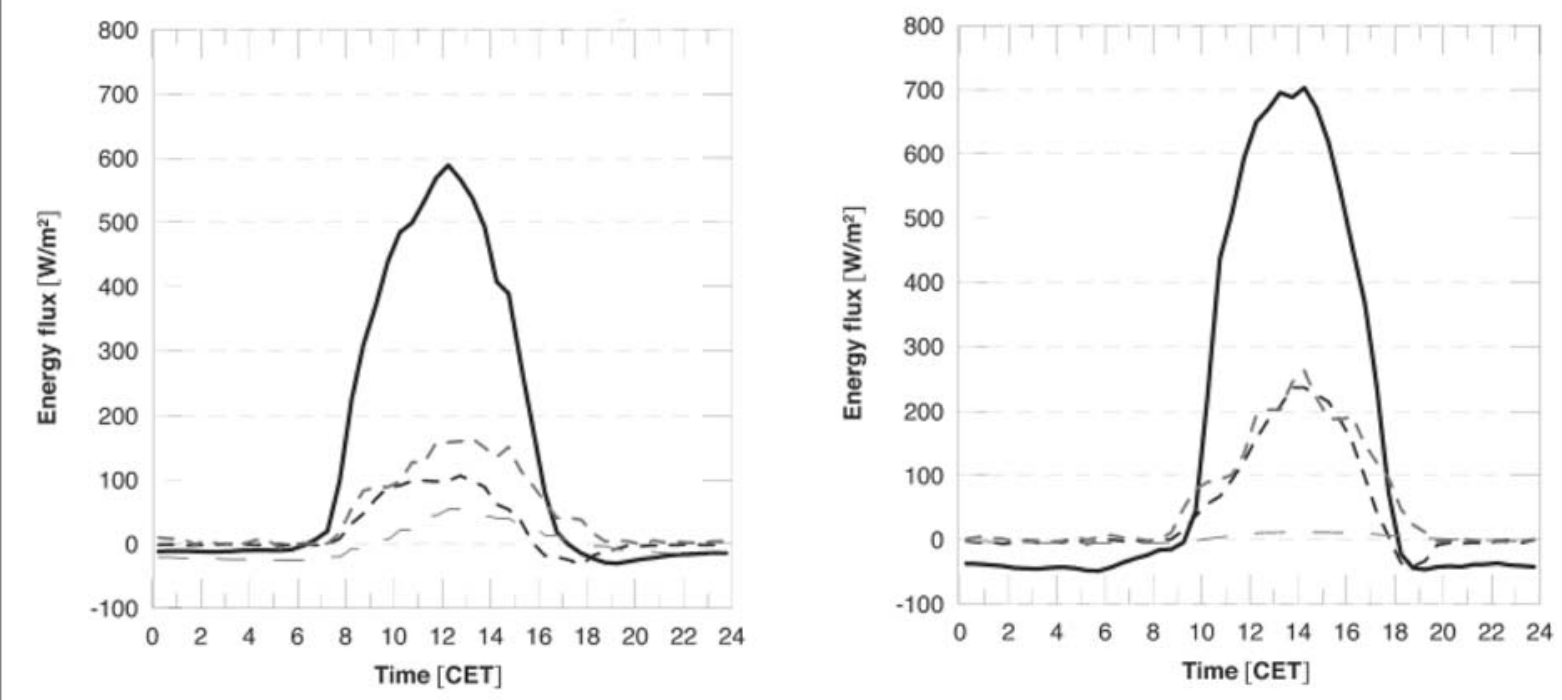

FIG. I2. Mean daily cycles of the components of the near-surface energy balance at (left) site Al and (right) B. Data are averages over 15 valley wind days (see text). The turbulent fluxes are measured at the respective lowest level at each of the sites (3.5 $\mathrm{m}$ at AI and I5 at B). Net radiation is observed at $2 \mathrm{~m}$ at AI and at $15 \mathrm{~m}$ at B. 
the energy balance are observed within a few meters and are relatively close to the surface, it is obvious from Fig. 12 that the idealized energy balance approach (i.e., $R_{n}=H+\mathrm{LE}+G$ ) for a flat and horizontally homogeneous surface cannot be applied in the type of environment investigated here. The full energy balance for a near-surface layer, including divergence of turbulent fluxes and advective processes, has to be assessed in detail in order to devise appropriate approaches for modeling purposes. Rotach et al. (2003) have demonstrated that vertical advection into an idealized box between the height of observation and the surface is likely to make up the energy gap, as is evident from Fig. 12. However, small magnitudes of the vertical velocity make it extremely difficult to determine the vertical advection term to reliable accuracy.

The situation at the slope site B is similar, albeit less extreme (Fig. 12). Due to the inclination of the slope net radiation reaches larger absolute values, and the maximum is obtained later in the day than at the valley floor (Matzinger et al. 2003). The turbulent fluxes, $H$ in particular, at the canopy top are larger in magnitude than at site A1, but their sum is still much too small to close the simple energy balance equation. Again, while Fig. 12 shows an average over 15 valley wind days, the individual days exhibit very similar daily cycles of the contributions to the energy balance.

The present dataset yields the possibility to investigate in detail a proper description of the surface energy balance in complex terrain. In particular, it will be interesting to assess to what extent local circulations driven by variations in the surface energy balance itself are important in explaining the observed energy fluxes.

Boundary layer height in a valley. The exchange of air between the valley boundary layer and atmosphere aloft, and the exchange between neighboring valleys are key processes in the investigation of air pollutant dispersion in valley atmospheres in which a major proportion of the population in mountainous terrain resides. Characteristics of this exchange are largely determined by the behavior of the boundary layer height and thermally driven circulation in a valley.

The discussion in connection with Fig. 9 has shown that the inversion height may not, in general, be regarded as the boundary layer height. The depth of the well-mixed portion in the valley atmosphere (if significant at all) corresponds neither to that of the valley wind layer nor to the depth of a layer of nonzero turbulence (Fig. 10). De Wekker (2002) and De Wekker et al. (2004) have, therefore, investigated in a case study the valley atmosphere using the various observations and a mesoscale model at high spatial resolution. The numerical model used was the RAMS (Pielke et al. 1992) with 4 two-way interactive nested grids down to a horizontal grid spacing of $0.333 \mathrm{~km}$. Model-simulated boundary layer height was determined using a Richardson number criterion.

For this case study the model was found to reproduce broad flow features in the Riviera valley. However, the simulated spatial variability was considerably larger than that observed, especially for the dynamic fields and also for the near-surface turbulence structure, that is the surface heat flux (De Wekker et al. 2004).

Model simulations indicated the boundary layer height to be relatively uniform along the valley axis and across the valley. For a clear sunny summer day with strong radiative heating and significant surface heat fluxes a modest "convective boundary layer height" of about $1300 \mathrm{~m}$ was reached in the afternoon. This corresponds to the height of observed nonnegligible turbulence on that day (Fig. 10). Note, however, that it does not correspond at all to the height of a "well mixed" regime for potential temperature (Fig. 9) or other scalars.

Presently, efforts in numerical simulation of the observations and numerical experimentation are intensified using the Advanced Regional Prediction System (ARPS) modeling system. Results from these efforts will be reported in forthcoming publications.

Hydrological processes. Hydrometeorological observations conducted at MAP-Riviera sites include soil moisture, soil temperature, soil heat flux, precipitation, and leaf interception, with all of these as time series having a high temporal resolution (Zappa et al. 2000). These data, which are available concurrently with the meteorological observations at towers in the Riviera valley, comprise a complete dataset for testing and validating soil-vegetation-atmosphere transfer schemes (SVATSs) of various degrees of complexity. SVATs are key features in both atmospheric and hydrological modeling systems, although important differences exist in the representation of the complexity of energetic and hydrological processes. SVATSs constitute the model interface for describing interactions between hydrological processes at the soil surface and subsurface, and atmospheric processes within the planetary boundary layer. They deal with spatial and temporal variations of evaporation, transpiration, interception, soil moisture, soil temperature, and the soil energy balance. The respective interactions generate continuous feedback on meteo- 

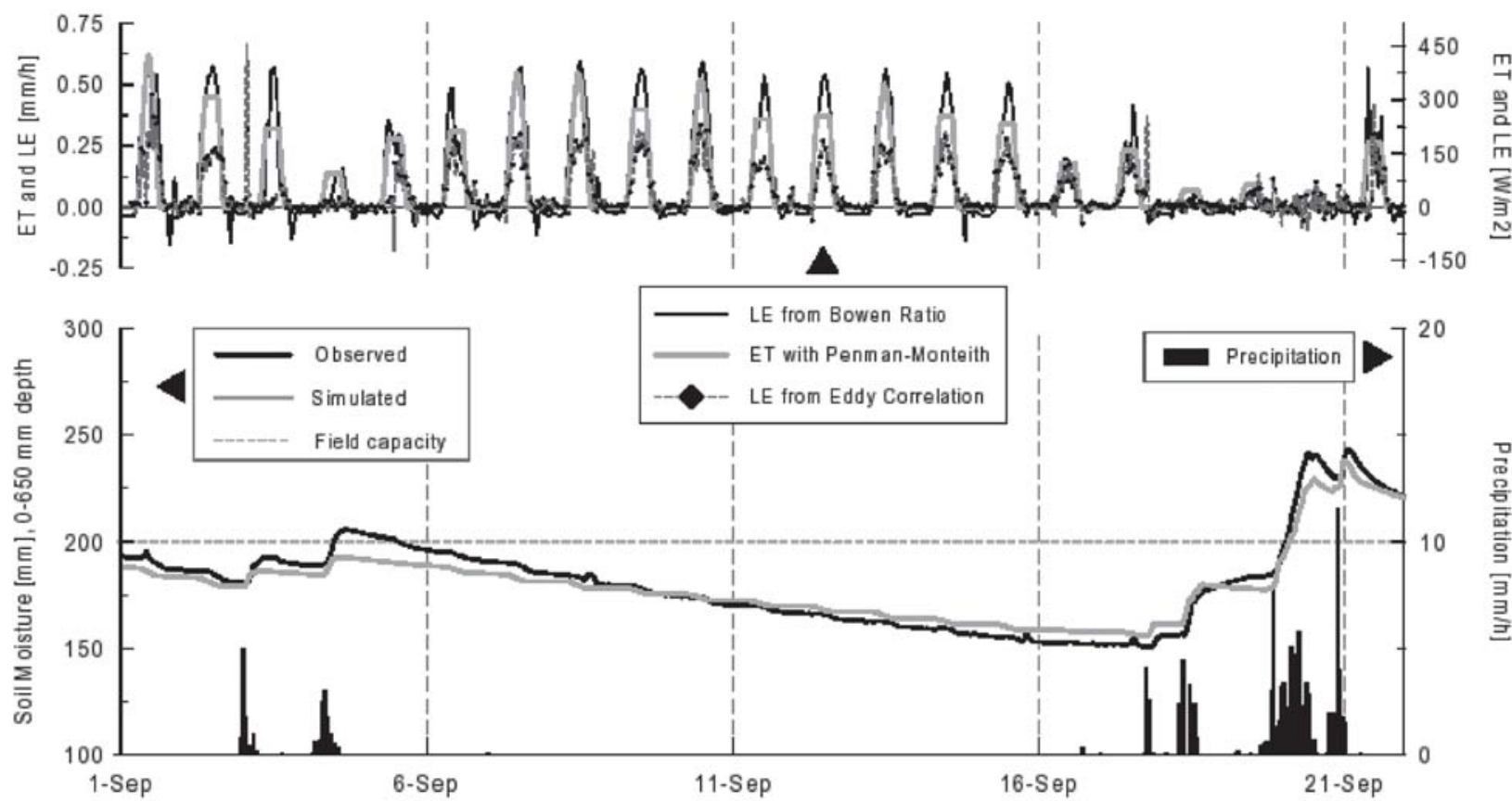

FIG. I3. (top) Time series of hydrological parameters for I-23 Sep I 999 at site AI. (bottom) Observed soil moisture integrated over a 0.65-m-deep layer (dark line) and simulated with the PREVAH hydrological model (labeled “Penman-Monteith"); dark columns indicate precipitation events (right scale). (top) Latent heat flux observed using eddy correlation (diamonds), calculated from temperature and humidity profiles using the Bowen ratio approach (dark line) and determined with the PREVAH model (gray lines), which uses the Penman-Monteith equation.

rological processes at various scales, on the site's energy and water balance, and on runoff generation processes. This highlights the importance of research leading to a consistent coupling of atmospheric and hydrological processes and models in complex terrain.

Figure 13 depicts a time series of some of the measured and modeled hydrological components at site A1 for the beginning of September 1999. The year 1999 was rather wet when compared to the climatological average resulting in relatively large soil moisture. The soil did not completely dry out, even during the 2-week period of fine weather (5-18 September). The decrease in soil moisture and subsequent recovery after the precipitation events are generally well captured by the Precipitation Runoff Evapotranspiration Hydrotope model (PREVAH) (Gurtz et al. 1999), though the depletion of soil moisture is somewhat underestimated by the model during the dry period. Both methods to determine the latent heat flux that use the energy balance equation (i.e., the Bowen ratio approach and the PREVAH model, which uses the Penman-Monteith approach) overestimate, as compared to the eddy correlation measurements. This is most likely related to the nonclosure of the near-surface energy balance at site
A1 (section titled Surface energy balance on a slope) during periods of fine weather. Figure 12 reveals that the sum of observed turbulent sensible and latent heat fluxes is substantially smaller than the observed available energy $R_{n}-G$. Thus, if a model assumes energy balance closure in its simplest form, it will overestimate the contribution of turbulent fluxes. If it should turn out that the missing energy is due to local advection and is a consequence of the valley wind system itself, this would have to give rise to a modification of these methods in complex terrain. This example nicely shows the mutual benefits in different research areas that can be gained through the collaborative nature of the MAP-Riviera project.

SUMMARY AND OUTLOOK. In the present paper an overview is provided of the scientific background and experimental arrangements of the MAP-Riviera project. This project aims at investigating the near-surface and boundary layer turbulent exchange processes in the presence of highly complex topography because it is the rule rather than the exception in the Alps and other major mountain ranges. During the experimental phase (JulyOctober 1999), a high-quality dataset was collected in the Riviera valley in southern Switzerland. It com- 
prises detailed near-surface turbulence measurements, profiles of mean meteorological variables throughout the valley atmosphere, and airborne observations of the mean and turbulence structure in the bulk of the valley. Also, two tracer release experiments were conducted. Detailed hydrological measurements at various sites within the valley complete the experimental efforts.

The Riviera dataset is presently being exploited to characterize and understand turbulent exchange processes near the surface, and between the valley atmosphere and free troposphere. Emphasis is given to the interaction of the local dynamic and thermodynamic fields (e.g., a thermally driven valley wind system) and the associated turbulence structure. The overall goal of the project lies in the evaluation and assessment of turbulence exchange parameterizations in meteorological and hydrological numerical models. Not only do we have a dataset at hand, which contains all the necessary variables to critically assess such parameterizations, but we also hope to use the results of the Riviera project to improve our understanding of the underlying processes. This, in turn will potentially lead to modified turbulence parameterizations for numerical models in complex terrain. First simulations with the mesoscale atmospheric model RAMS with simpler diagnostic models (not shown), and the hydrological runoff model PREVAH, are promising in the sense that they reveal some overall skill in reproducing the observed mean flow features. This is especially noteworthy because these models were used beyond their range of applicability. We mention here only the efforts that were necessary in order to obtain a stable integration for RAMS at the given high spatial resolution in the very steep orography of the Riviera valley. A careful analysis of both the observations and the model results clearly bears the potential to identify possible weaknesses in the numerics and physical parameterizations for mesoscale meteorological modeling in highly complex terrain. We anticipate that other models of various degrees of complexity will be involved in this process in the near future.

ACKNOWLEDGMENTS. Many individuals and institutions have contributed to the success of the MAP-Riviera project. Funds were available from the Swiss National Science Foundation (Grants 21-54060.98, 21-55874.98, and 20-63820.01), grants from the Natural Sciences and Engineering Research Council of Canada to D. G. Steyn and the European Joint Research Center (JRC) in Ispra (I). Support before and during the observational campaign of the local authorities of Claro, Switzerland, and in particular Mr. Pellegrini, is greatly appreciated. The passive micro- wave temperature profiler (MTP-5) was made available for the project by Kipp \& Zonen B.V. (Delft, the Netherlands) through the kind intervention of markasub AG (Basel, Switzerland) and Meteodat GmbH (Zürich, Switzerland). We are indebted to the Forschungszentrum Karlsruhe (Dr. N. Kalthoff) and to the Paul Scherrer Institute (Dr. M. Furger) for lending us a number of sonic anemometers. Karl Schroff and Hansjürg Frei from ETHZ, as well as Valentino Badà and N. Cao from JRC were key people in the preparation, construction, and maintenance of all of the countless surface towers, the instrumentation, and the necessary facilities. Many thanks go to a large number of students and other individuals who helped in the field to operate and maintain the instrumentation, download the data, and operate the radio sounding system: A. Bassi, S. Bethke, S. Carlaw, M. Dippon, C. Feigenwinter, A. Felber, C. Heinemann, S. Hoch, F. Imbery, P. Keller, N. Matzinger, E. Müller, M. Müller, P. Müller (from the workshop of MCR-Lab), O. Rahs, M. Raymond, S. Regazzi, J. Sedlacek, S. Seneviratne, and S. Zimmermann. Finally, we acknowledge the very helpful and constructive comments of two anonymous referees, which made the paper more readable and understandable.

\section{REFERENCES}

Andretta, M., S. Zimmermann, M. W. Rotach, P. Calanca, A. Christen, and R. Vogt, 2000: Investigation of the near-surface boundary-layer in an Alpine valley. MAP Newsletter, Vol. 13, 68-69.

—, A. Weiss, N. Kljun, and M. W. Rotach, 2001: Nearsurface turbulent momentum flux in an Alpine valley: Observational results. MAP Newsletter, Vol. 15, 122-125.

Anfossi, D., D. Desiato, G. Tinarelli, G. Brusasca, E. Ferrero, and D. Sacchetti, 1998: TRANSALP 1989 experimental campaign-II: Simulation of tracer experiments with Lagrangian particle model. Atmos. Environ., 32, 1157-1166.

Belcher, S. E., and J. C. R. Hunt, 1998: Turbulent flow over hills and waves. Ann. Rev. Fluid Mech., 30, 507538.

Beljaars, A. C. M., and P. Viterbo, 1998: Role of the boundary layer in a numerical weather prediction model. Clear and Cloudy Boundary Layers, Proceedings of the Colloquium "Clear and Cloudy Boundary Layers," Amsterdam 26-29 August 1997, A. A. M. Holtslag and P. G. Duynkerke, Eds., Edita KNAW, 287-304.

Binder, P., and C. Schär, Eds., 1996: The Mesoscale Alpine Programme: Design proposal. MAP, 77 pp. [Available from MAP Programme Office, c/o Swiss Meteorological Institute, $\mathrm{CH}-8044$ Zürich, Switzerland.] 
Bougeault, P., and Coauthors, 2001: The MAP special observing period. Bull. Amer. Meteor. Soc., 82, 433-462.

Calanca, P., M. W. Rotach, A. Andretta, R. Vogt, E. Van Gorsel, and A. Christen, 2000: The turbulence structure in an Alpine valley. Preprints, Ninth Conf. on Mountain Meteorology, Aspen, CO, Amer. Meteor. Soc., 235-236.

Carlaw, S. M., N. Kouwen, and E. D. Soulis, 2000: The significance of soil moisture in flood forecasting. Abstracts, Annual Scientific Meeting, Banff, AB, Canada, Canadian Geophysical Union.

Christen, A., E. Van Gorsel, M. Andretta, P. Calanca, M. W. Rotach, and R. Vogt, 2000: Field intercomparison of ultrasonic anemometers during the MAPRiviera project. Preprints, Ninth Conf. on Mountain Meteorology, Aspen, CO, Amer. Meteor. Soc., 130131.

_ - _ R. Vogt, M. Andretta, and M. W. Rotach, 2001: Ultra sonic anemometer instrumentation at steep slopes: Wind tunnel study-field intercomparisonmeasurements. MAP Newsletter, No. 15. [Availablel online at www.map.ethz.ch/NL15/christen.pdf.]

Cionco, R. M., and Coauthors, 1999: An overview of MADONA: A multinational field study of highresolution meteorology and diffusion over complex terrain. Bull. Amer. Meteor. Soc., 80, 5-20.

Clements, W. E., J. A. Archuleta, and P. H. Gudiksen, 1989: Experimental design for the 1984 ASCOT field study. J. Appl. Meteor., 28, 405-413.

De Wekker, S. F. J., 2002: Structure and morphology of the convective boundary layer in mountainous terrain. Ph.D. dissertation, The University of British Columbia, $191 \mathrm{pp}$.

- , D. G. Steyn, M. W. Rotach, J. D. Fast, and S. Zhong, 2002: Observations and numerical modeling of the daytime boundary layer structure in the Riviera Valley, Switzerland. Preprints, 10th Conf. on Mountain Meteorology, Park City, UT, Amer. Meteor. Soc., 35-38.

— _ _ - J. D. Fast, M. W. Rotach, and S. Zhong, 2004: The performance of RAMS in representing the convective boundary layer structure in a very steep valley. J. Environ. Fluid Mech., in press.

Emeis, S., and M. W. Rotach, 1997: Working group on planetary boundary-layer (WG-PBL). MAP Newsletter, Vol. 6, 13-19.

Furger, M., and Coauthors, 2000: The VOTALP Mesolcina Valley Campaign 1996-Concept, background and some highlights. Atmos. Environ., 34, 1395-1412.

Georgelin, M., E. Richard, M. Petitdidier, and A. Druilhet, 1994: Impact of subgrid-scale orography parameterization on the simulation of orographic flows. Mon. Wea. Rev., 122, 1509-1522.
Girardi, F., G. Graziani, D. van Veltzen, S. Galmarini, S. Mosca, R. Bianconi, R. Bellasio, and W. Klug, Eds., 1998: The ETEX project. Office for Official Publications of the European Communities EUR Rep. 18143, EN, 108 pp.

Gurtz, J., A. Baltensweiler, and H. Lang, 1999: Spatially distributed hydrotope-based modelling of evapotranspiration and runoff in mountainous basins. Hydrol. Processes, 13, 2751-2768.

Holtslag, A. A. M., and F. T. M. Nieuwstadt, 1986: Scaling the atmospheric boundary layer. Bound.Layer Meteor., 36, 201-209.

Jackson, P. S., and J. C. R. Hunt, 1975: Turbulent windflow over a low hill. Quart. J. Roy. Meteor. Soc., 101, 929-955.

Kadygrov, E. N., and D. R. Pick, 1998: The potential for temperature retrieval from an angular-scanning single channel microwave radiometer and some comparisons with in-situ observations. Meteor. Appl., 5, 393-404.

—, V. Kadygrov, E. Miller, H. Weber, and M. W. Rotach, 2001: The thermal structure of the atmospheric boundary layer in an Alpine valley: Results of continuous remote sensing measurements and comparison with radiosonde data. IRS 2000: Current Problems in Atmospheric Radiation, W. L. Smith and Yu M. Timofeyer, Eds., A. Deepak Publishing, 10971101.

Kuwagata, T., and F. Kimura, 1995: Daytime boundary layer evolution in a deep valley. Part I: Observations in the Ina Valley. J. Appl. Meteor., 34, 1082-1091.

Louis, J. F., 1979: A parametric model of vertical fluxes in the atmosphere. Bound.-Layer Meteor., 17, 187-202.

Matzinger, N., M. Andretta, E. Van Gorsel, R. Vogt, A. Ohmura, and M. W. Rotach, 2003: Surface radiation budget in an alpine valley. Quart. J. Roy. Meteor. Soc., 129, 877-895.

Neininger, B., W. Fuchs, M. Bäumle, A. Volz-Thomas, A. H. S. Prevot, and J. Dommen, 2001: A small aircraft for more than just ozone: Metair's Dimona after ten years of evolving developments. Preprints, 11th Symp. on Meteorological Observations and Instrumentation, Albuquerque, NM, Amer. Meteor. Soc., 123-128.

Pielke, R. A., and Coauthors, 1992: A comprehensive meteorological modeling system-RAMS. Meteor. Atmos. Phys., 49, 69-91.

Plüss, C., and R. Mazzoni, 1994: The role of turbulent heat fluxes in the energy balance of high Alpine snow cover. Nord. Hydrol., 25, 25-38.

Randall, D. A., 2001: Representing the turbulent boundary layer in global atmospheric models. Geophys. Res. Abstr., 3, p. 4163. 
Rotach, M. W., 1995: On the boundary layer over mountainous terrain-A frogs perspective. MAP Newsletter, Vol. 3, 31-32.

—, P. Calanca, R. Vogt, D. G. Steyn, G. Graziani, and J. Gurtz, 2000: The turbulence structure and exchange processes in an Alpine valley: The MAPRiviera project. Preprints, Ninth Conf. on Mountain Meteorology, Aspen, CO, Amer. Meteor. Soc., 231-234.

,,-- A. H. Weigel, and M. Andretta, 2003: On the closure of the surface energy balance in highly complex terrain. Extended Abstracts Vols. A and B, Int. Conf. on Alpine Meteorology and MAP Meeting 203, Veröffentlichungen der MeteoSchweiz, 66, 247-250.

Van Gorsel E., A. Christen, E. Parlow, and R. Vogt, 2000: Micrometeorological measurements at an alpine slope. Preprints, Ninth Conf. on Mountain Meteorology, Aspen, CO, Amer. Meteor. Soc., 237-238.

,,--- , and —, 2001: Momentum transport in and above a forest at a steep slope. MAP Newsletter, No. 15. [Available online at www.map.ethz.ch/ NL15/gorsel.pdf.]

,$- \ldots$, C. Feigenwinter, E. Parlow, and R. Vogt, 2003: Daytime turbulence statistics above a steep forested slope. Bound.-Layer Meteor., 109, 311-329.

Vergeiner, I., 1987: An elementary valley wind model. Meteor. Atmos. Phys., 36, 255-263.

Vogt, R., C. Bernhofer, L. W. Gay, L. Jaeger, and E. Parlow, 1996: The available energy over a Scots Pine plantation: What's up for partitioning? Theor. Appl. Climatol., 53, 23-31.

Weigel, A. H., and M. W. Rotach, 2003: On the turbulence structure in a daytime alpine valley. Extended Abstracts Vols. A and B, Int. Conf. on Alpine Meteorology and MAP Meeting 203, Veröffentlichungen der MeteoSchweiz, 66, 162-165.

Weiss, A., 2002: Determination of thermal stratification and turbulence of the atmospheric surface layer over various types of terrain by optical scintillometry. Ph.D. thesis, Swiss Federal Institute of Technology, ETH Dissertation 14514, 153 pp.

—, M. W. Rotach, and M. Hennes, 1999: Comparison of turbulence parameters derived from optical scintillation and eddy-correlation technique over flat terrain. Preprints, 13th Symp. on Boundary Layer and Turbulence, Dallas, TX, Amer. Meteor. Soc., 145-146.

—, M. Hennes, and M. W. Rotach, 2001: Derivation of refractive index and temperature gradients from optical scintillometry for the correction of atmospheric induced problems in highly precise geodetic measurements. Surv. Geophys., 22, 589-596.

Whiteman, C. D., 1990: Observations of thermally developed wind systems in mountainous terrain. Atmospheric Processes over Complex Terrain, Meteor. Monogr., No. 45, Amer. Meteor. Soc., 5-42.

- 2000: Mountain Meteorology. Oxford University Press, 355 pp.

— K. J. Allwine, L. J. Fritschen, M. M. Orgill, and J. R. Simpson, 1989a: Deep valley radiation and surface energy budget microclimates. Part I: Radiation. J. Appl. Meteor., 28, 414-426.

$-,-, \ldots, \ldots$, and ——, 1989b: Deep valley radiation and surface energy budget microclimates. Part II: Energy budget. J. Appl. Meteor., 28, 427437.

Zappa, M., N. Matzinger, and J. Gurtz, 2000: Hydrological and meteorological measurements at Claro $(\mathrm{CH})$-Lago Maggiore Target Area in the MAP-SOP 1999 RIVIERA experiment including first evaluation. Hydrological Aspects in the Mesoscale Alpine Programme-SOP Experiment, Tech. Rep. of the Department of Civil Engineering 10(2), University of Brescia, 33 pp. 